Erik Mogstad has a master's degree in science education from the Norwegian University of Science and Technology in Trondheim. He teaches science and mathematics in lower secondary school and is involved in work with research and development of science education at the university's resource centre for mathematics, science and technology education ("Skolelaboratoriet").

Berit Bungum is professor of science education at the Norwegian University of Science and Technology in Trondheim. She has many years experience with teacher education in science, and works with teachers' professional development and development of teaching resources at the university's resource centre for mathematics, science and technology education ("Skolelaboratoriet").

\title{
ERIK MOGSTAD
}

The Norwegian University of Science and Technology, Department of Physics, Norway. erik.mogstad@ntnu.no

\section{BERIT BUNGUM}

The Norwegian University of Science and Technology, Department of Physics, Norway. berit.bungum@ntnu.no

\section{Ski lifts, bowling balls, pipe system or waterfall? Lower secondary students' understanding of analogies for electric circuits.}

\begin{abstract}
Electric circuits are challenging for students to understand, and a wide range of analogies are developed in order to support their learning. This article investigates how lower secondary students understand four analogies presented in teaching material for science for Norwegian schools. The analogies compare electric circuits to a ski lift, a water pipe system, a waterfall and moving bowling balls, respectively. Data in the study consist of group interviews with 12 students in lower secondary school, about how they understand the analogies. Results show that students are able to reason about continuity and the concept of current in circuits based on all the analogies, but that the concept of voltage remains a challenge. It seems from the results that analogies relating voltage to energy transfer as an effect of height difference in a gravitational field are constructive, despite the need for the more abstract concept of field. In addition, the results demonstrate that weaknesses in how the analogies are presented may cause major problems for students in building a fruitful understanding. This kind of weaknesses are prevalent in the teaching material studied.
\end{abstract}

\section{INTRODUCTION}

Analogies are widely used in science teaching in order to support students' understanding of concepts and relationships. The purpose of an analogy is to compare new concepts and relationships to similar identities in a domain that is known to the learner (see Gilbert \& Justi, 2016). Electric 
circuits are a topic in which analogies are of particular use, since it involves quite abstract concepts such as current, voltage, resistance, energy and power, and relations between these concepts. A wide range of misconceptions about electric circuits are documented and well known (see e.g. Shipstone et al., 1988). However, research on what kind of analogies that best support students' understanding of electric circuits is still incomplete and fragmented.

This article reports an interview study of how lower secondary students (age 14-15) understand four different analogies for electric circuits found in Norwegian teaching material for lower secondary school science. The study is based on a theoretical analysis of the same four analogies (Mogstad, 2016), by means of structure mapping theory (Gentner, 1983). Structure mapping means to investigate how concepts and relationships in a target domain (the new domain to be learnt) compare to the corresponding concepts and relationships in the known source domain used in the analogy. Results showed that all the analogies had a functional relationship between the source and target domain, but that the presentation lacks information about limitations and some lack sufficient explanation of the source domain.

The research question for the interview study is:

How do lower secondary students understand analogies for electric circuits presented in teaching material?

The way analogies are presented in textbook and teaching is crucial for students' understanding (Coll, France, \& Taylor, 2005), and the results will therefore reflect the quality of presentation and not only the ideas inherent in the analogies as such or a particular teaching approach. The data collection is therefore undertaken with students one year after they have learnt about electric circuits in lower secondary school, in order to investigate how students who are supposed to have some knowledge of circuits, understand the different analogies presented in textbooks. Their understanding is of course influenced by prior education, but the study is not about how students recall what they learnt in school a year earlier. It is rather about how analogies for electric circuits are understood by a relevant age group supposed to have some prior knowledge of the content. The analysis draws on theoretical principles from structure mapping (Gentner, 1983).

In the following, we first present concepts and principles of structure mapping and challenges in learning with analogies. Then follows a review of students' challenges in understanding electric circuit, before we present the analogies that are investigated and details of the sample and research methods. Results of the interviews are then presented for each analogy before a final discussion.

\section{STRUCTURE MAPPING AND CHALLENGES IN LEARNING WITH ANALOGIES}

The use of analogies entails a comparison between two phenomena, systems or principles that possess one or more similarities, in order to describe abstract and/or unknown concepts (see e.g. Gilbert \& Justi, 2016). Analogies consist of what Gentner (1983) has denoted a source domain (also referred to as base domain) and a target domain, where objects and relations between them in the target domain are compared with those of a more well-known source in order to promote understanding of the unfamiliar target. With structure mapping theory, Gentner (1983) created a framework for analysing relations between objects in source and target domains and how mapping of these relations can be undertaken. 'Mapping' here entails to identify relations between objects in the domains, referred to as shared relations. Gentner underlines that what is to be mapped between source and target domain are relations between the objects and not specific attributes (properties) of objects. Higher order relations mean that also relations between object relations are preserved between the source and target domain.

Research has revealed a range of challenges for students in learning science with analogies (Brown \& Salter, 2010; Coll et al., 2005; Duit, 1991; Glynn, 1989). Students may misinterpret how the target domain relate to the source domain, the use of analogies may in itself produce misconceptions, and 
misunderstandings due to unshared relations between the analogy's domains In a more recent review of research on the use of analogies in science teaching, Gilbert and Justi (2016) noted that students may have problems understanding the source domain that is meant to help them understand the target domain. Students may also interpret analogies too literally: Students may be "naïve scientist" and possess an epistemology where there is a 1:1 relation between models (including analogies) and reality. They may believe that scientific models are exact replicas of the reality they experience (see e.g. Treagust, Chittleborough, \& Mamiala, 2002).

As a potential way of helping instructors in the development and use of analogies, (Glynn, 1989) proposed "The teaching with analogies model" (TWA). Previous studies have shown positive result in learning and understanding new concepts, and avoiding misconceptions, through the use of TWA as a model for instruction (Glynn \& Takahashi, 1998; Harrison \& Treagust, 1993). However, other studies have found that analogies in textbooks rarely adheres to all the recommendations from TWA. Mapping and information about limitations of the analogy is especially rare to be found explicitly described in textbooks (Hedberg, Haglund, \& Jeppsson, 2015; Thiele \& Treagust, 1994).

\section{STUDENT CONCEPTIONS ABOUT ELECTRIC CIRCUITS}

Electric circuits have been subject to a wide range of studies of student conceptions over several decades, and a range of misconceptions are documented. Based on the early work of Kärrqvist (1985) and other studies through several decades, students' misconceptions and alternative models are usually described by the following categories (for good overviews, see e.g. Leone, 2014; Rengman, Johansson, \& Jeppsson, 2010; Tarciso Borges \& Gilbert, 1999): The unipolar model, where the electric circuit is not closed; the clashing current model, where the current flows from both poles of the battery and the light may be explained in terms of the "clash" of the two currents; and the current consumption model, where there is less current in wire going back to the battery since it is "consumed" by the bulb. Kärrqvist (1985) also described a constant current source model where the current is constant, determined by the battery and independent of circuit features. A fifth category represents the scientific model involving Ohm's law. It is also shown that students often have problems with viewing a circuit as a whole, and they may interpret circuits by use of local and sequential reasoning (Liégeois \& Mullet, 2002), where each component is treated separately and can only affect subsequent components and not the entire circuit.

The challenges in comprehending the circuit as a continuous, integrated system may be due to weak conceptions of voltage. Many studies indicate that students tend to have current as their principal concept rather than voltage (see e.g. Kokkonen \& Mäntylä, 2017). When students consider voltage, they often see it as a consequence rather than a cause of electric current (Cohen, Eylon, \& Ganiel, 1983), have problems differentiating between voltage and current, or they do not see why both concepts are needed (Koponen \& Huttunen, 2013). It is shown that even university students in physics have difficulties understanding relations between concepts (Kokkonen \& Mäntylä, 2017), and that textbooks in electrical engineering at university level tend to contain 'conceptual gaps' where important conceptual features are missing in the treatment of electric circuits (Sangam \& Jesiek, 2015).

Since reasoning about electric circuits with current rather than voltage as a principal concept is unconstructive for building an understanding, it has been suggested that teaching about electric circuits should have electric field as its starting point in order to support development of a constructive conception of voltage. For example, Stocklmayer (2010) developed a teaching model for high school students based on evolvement of the concept of field from everyday experiences to gravitational, magnetic field and electrostatic field, and finally applying established field principles to electric circuits. Classroom trials indicated that even if the field model appears more difficult than the traditional electron flow model, it has stronger explanatory power and may be more constructive for high school students in developing constructive conceptions of electric circuits. 


\section{RESEARCH ON ANALOGIES FOR ELECTRIC CIRCUITS IN TEACHING}

Despite the large amount of research undertaken on students' conceptions of electric circuits and the many attempts to support students' understanding be means of analogies in teaching on lower levels, there is little recent research on how students understand these analogies. Back in 1983, Gentner and Gentner (1983) investigated three different analogical models for electric circuits by means of structure mapping, and how students on high school / college level relying on these models solved problems with electric circuits. They found systematic differences in patterns of explanations, for example that students relying on a flowing fluid model did better with batteries, while relying on a model with moving objects was associated with better results on tasks about resistors. Dupin and Johsua (1989) used an experimental design to investigate students' learning outcome after teaching involving a train analogy and an analogy involving heat conduction as alternative to the widely used water model. They found better results among students taught by means of the analogies, but also that both analogies had limitations in explaining features of an electric circuit.

Chiu and Lin (2005) studied learning outcomes for young students (4th grade) by teaching that used several analogies for electric circuits. They suggest that use of multiple analogies is beneficial for young students' understanding of current in circuits, since all analogies have limitations. This relates to how D. E. Brown and Clement (1989) describe bridging analogies where one uses a series of analogies to supplement and correct weaknesses in a previous analogy.

Paatz, Ryder, Schwedes, and Scott (2004) used structure mapping in a case study on how an extensive teaching unit on water flow in pipes in upper secondary school physics. The teaching involved experimenting with physical models of a water flow system. Results indicated that the water pipe analogy may be constructive, provided that the student is well familiar with the source domain used in the analogy, as also emphasized by e.g. Gilbert and Justi (2016).

These empirical studies involved extensive teaching time allocated to learning about electric circuits by means of the chosen analogies. The study reported in this article contributes to the field by investigating how lower secondary students understand analogies for electric circuits described in textbooks without extensive teaching time allocated, a situation that reflects what is likely to be the case in many schools.

\section{ANALOGIES USED IN THIS STUDY}

Four analogies were selected for the study. Two were chosen from commonly used textbooks in science for lower secondary school, and the third from a textbook for physics in upper secondary school. The fourth analogy is found in material used in professional development courses for teachers. It was included since it complemented the ones from the textbooks and believed to be comprehendible for the students. We here describe the four analogies investigated in this study.

Analogy 1, Ski lift (Figure 1), is from a textbook for grade 9 (Ekeland, Johansen, Strand, Rygh, \& Jenssen, 2008). The textbook makes use of a ski lift as an analogy for movement of charge in an electric circuit. Electrons are compared to the ski lift chairs, focusing on how they will all start and stop their movement simultaneously. The ski lift motor is compared with a battery due to its role as a driving force in the circuit, and voltage hence compares to the height to which the skiers are lifted.

Analogy 2, Pipe system (Figures 2a and 2b) is from a textbook for grade 9 (Hannisdal, Haugan, \& Munkvik, 2007). The textbook uses the pipe system analogy in two slightly different ways When the textbook makes use of the illustration where the pipe system has a container (Figure 2a), a water pump's ability to supply energy to the water molecules by elevating them, is compared to a battery's ability to create a difference in potential between its two terminals. Voltage here compares to the power of the pump, and in the case with a container possibly also elevation of water level. When the textbook makes use of the illustration with a turbine (Figure 2b), the ability of moving water and electrical current to "give away energy" (Hannisdal et al., 2007, p. 212, our translation) is compared. 
Analogy 3, Waterfall (Figure 3), is from a textbook for physics in upper secondary school (Jerstad, Sletbak, Grimenes, \& Renstrøm, 2007). The textbook makes use of the waterfall analogy when presenting the concept of voltage. It describes a source domain where a water pump transports water from the bottom of a mountain to the top, and how the energy required for lifting the water is analogous to the energy from a battery in a circuit. Voltage compares to the power of the pump, or the height water is lifted resulting from the work performed by the pump.

Analogy 4, Bowling balls (Figure 4), is from a course booklet for science teachers (Rossing, 2005). The course booklet describes how a bowling ball needs gravity and mass in order to perform work, and that this object relation is analogous to the need of an electrical field and charge in order to create potential energy in a circuit and hence that work can be done in e.g. a light bulb. Again, voltage compares to height in the analogy.

The chosen analogies represent what is available in Norwegian teaching context for lower secondary school, and concepts such as "random motion" is therefore not included.

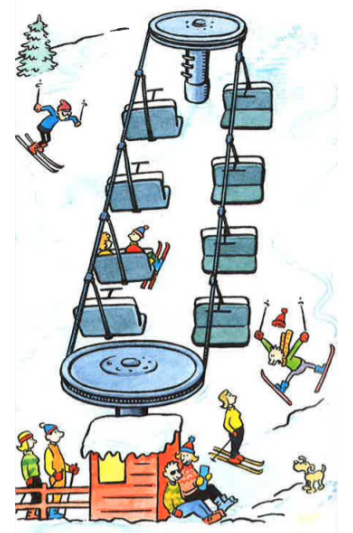

Figure 1. Analogy 1, Ski lift (Ekeland et al., 2008).
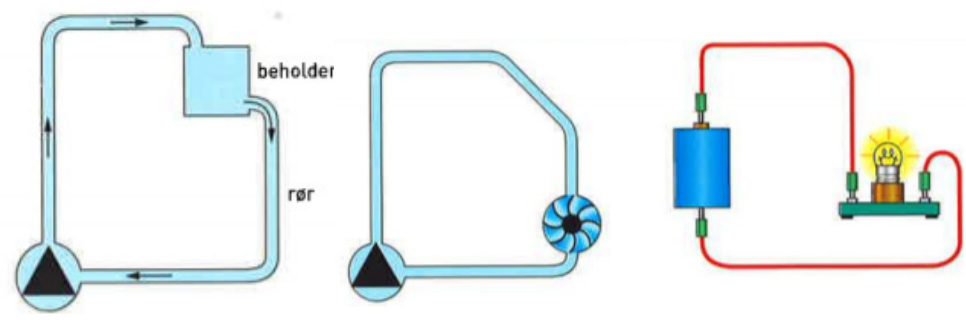

Figure 2. Analogy 2, Pipe system a) with container and b) with turbine (Hannisdal et al., 2007).

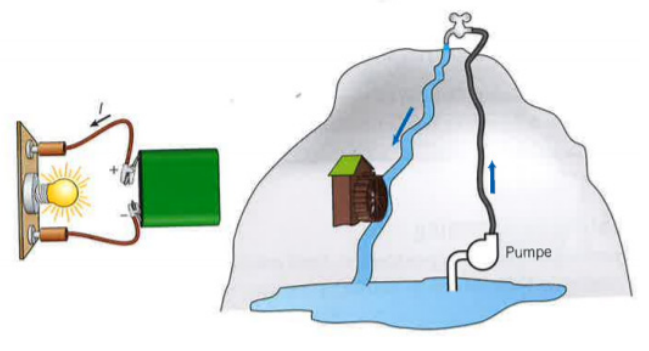

Figure 3. Analogy 3, Waterfall (Jerstad et al., 2007).
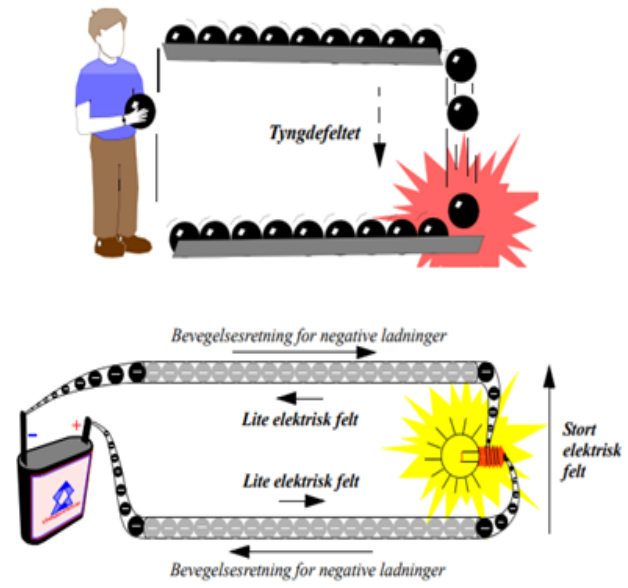

Figure 4. Analogy 4, Bowling balls (Rossing, 2005). 


\section{RESEARCH METHODS}

The study is based on interviews with students about the analogies presented in the forgoing. We do not trace individual students' conceptions across the different analogies, since the focus is on the analogies and how students may understand them.

\section{Sample of students}

Interviews were conducted with 12 students ( 5 girls and 7 boys) in grade 10. This grade was considered appropriate because students at this level have been taught electricity from the curriculum for lower secondary school the previous year.

The informants were selected from two different schools where they were taught by four different teachers, in order to minimize a teacher bias on the results, since teacher effects are dominant factors affecting students' academic gains (Sanders, Wright, \& Horn, 1997). The four teachers were well qualified in science, but none were experts beyond what is typical for teachers in Norwegian lower secondary school. Teachers were also purposefully selected with regards to that they use two different textbooks, in order to reduce bias in preferences students had acquired from their own textbook. The selected students had medium to high level of achievement in science. The transferability of results from this study is hence limited to students of a corresponding ability range.

\section{Data collection}

The 12 students were interviewed in pairs, in order to open for discussion between the two students, and to avoid too high pressure on them.

The interviews were undertaken by the first author of this paper. They were semi-structured and lasted typically around 60 minutes. The first few minutes consisted of conversation about different electrical concepts, such as current and voltage. This was done both to get the students talking and comfortable and to get hold of information about their knowledge on concepts form electricity. Then the analogies were presented to students and discussed one by one. The order in which the analogies where presented and discussed varied, but the first analogy of an interview was always from the textbook the students used when they were taught electricity at school. The reason for this was the judgment that it might be easier to start discussing and analyzing an analogy they previously had worked with. This resulted in that half of the student was presented with the ski lift analogy first, and the other half the pipe system analogy. The student was not given the opportunity to study any of the analogies beforehand, but the interviewer was conscious on the use of probing during the interviews. As described by e.g. L. Cohen, Manion, and Morrison (2011), this may facilitate discussion and reflection on the content of the interview.

\section{Data analysis}

The interviews were tape-recorded and fully transcribed. The transcribed interviews were analyzed by thematic coding (Braun \& Clarke, 2006) with emerging themes from the empirical data as well as from literature on analogies and student conceptions of electric circuits. The concepts and principles from structure mapping (Gentner, 1983) presented in the foregoing were used in the analysis and presentation as a conceptual framework, for example to define when students where mapping valid shared object relations between domains, shared or unshared attributes or mere structural similarities.

Analysis was undertaken with regards to each analogy, not individual students, but individual students can still be traced through the presentation of results through the consistent use of fictitious names. 


\section{RESULTS}

This section presents interview results for each of the four analogies investigated: the ski lift, the pipe system, the waterfall and the bowling balls. When students discuss analogies from a textbook they previously have used it is commented in brackets.

\section{Analogy 1: Ski lift}

Interview data suggest that the ski lift as analogy communicates the shared relations between the ski lift and the target domain in ways that are comprehendible for the grade 10 students. They are able to relate movement of objects (ski lift carriages) in the lift and the movement of objects (charges) in an electric current, and describe how this movement is continuous in the sense that movement of objects is equally independent of its position in the system. For example, in the interview with George and Mark (who have had this analogy in their school textbook), they describe it this way (I: interviewer):

I: What do you think about this ski lift for explaining various properties of electricity?

George: It explains the movement of current quite well

I: How, do you reckon?

George: Well, it follows the movement quite well in that the carriages go equally. That is, if you imagine marbles in a tube, they will fall out once you push a new one in. It happens simultaneously.

I: And you see this in relation to what happens inside the wires of an electric circuit?

Mark: Yes, because the electrons move, and then they are pushed away in the same way as when you press in a new marble. Then one falls out in the other end. (...) When you make the ski lift move, then the chair will move, and since it is attached to the entire network then all of them will move in the same direction and with the same speed. And the same acceleration.

Interestingly, the students here explain the analogy with the use of another analogy - a row of marbles in a tube. They correctly identify shared relations between the two source domains and the electric circuit in that the movement of carriages/marbles/electrons is equal in the entire circuit.

Most students are able to see a shared relation in that the system is dependent on a driving force, and relate the lift motor to the battery in the electric circuit. However, problems appear in all groups of students when they are challenged to identify what electric voltage relates to in the ski lift analogy. In the following interview example, students Robert and David have mentioned voltage as one of the concepts relevant for describing an electric circuit. They are then asked how current and voltage relate to objects in the ski lift analogy:

David: I guess it is the carriages that are, in a way, the current. They are like electrons, travelling around the circuit.

Robert: Yes, and the motor is the voltage.

I: In what way is the motor of the ski lift like the voltage?

David: It is... well...

Robert: Because it is the motor that runs the entire ski lift

I: How does it run the ski lift?

David: I am not really an expert on ski lift motors, but...

I (laughing): Neither am I!

Robert: It runs on current and... there is some machine in there that makes the wheel rotate.

The students here show insights in the role of voltage in a circuit as they associate it with energy supply (a driving force) in the circuit. This makes them point to the motor as the object that relates to voltage in the circuit. This would be correct for a battery, i.e. the source of voltage, which is more concrete and more understandable for the students. When elaborating on what voltage means in the analogy, Student 1 points to the fact that the motor "runs on current", which may signal a misconception of voltage as a result of electric current. It also indicates that the electricity associated with the ski lift analogy may be counteractive for students' understanding, because it involves electricity as an unshared attribute between objects in the source domain and the target domain. 


\section{Erik Mogstad and Berit Bungum}

The analogy and the drawing can also be understood in a quite different way, where the circuit relates to both the ski lift and the ski slope where the skiers run down. The entire ski lift, not only the motor, will then correspond to how a battery gives electrons energy, by giving skiers potential energy that they thereafter may "spend" in various ways going downhill. This interpretation was not intended in the textbook where the analogy is drawn from in this study, but is of use elsewhere, for example in a textbook used in physics in upper secondary schools in Norway (see Bungum, 2008). Still, one of the students, John, actually uses this more abstract interpretation of the analogy:

John: It is possible to think of the people as, sort of, electrons.

I: Ok?

John: And then it <the lift> pulls the electrons in a direction. I don't know... but the people get higher energy on the top than when they are at the bottom.

I: The people get...?

John: Yes, but I am not sure.

I: No, but if we stick to this, that the people get higher energy at the top. What do you mean? Go on. John: Well... when they are on the top of the hill they have higher... what's it called... elevation force... I don't know... potential energy it is!

William: We have learnt about that.

John: Yes, so they have higher potential energy when they are at the top than here at the bottom, and the battery can, sort of, be the lift. That gives them potential energy when they are at the top.

In this interpretation of the analogy, the potential energy is transferred via friction when skiers are on their way down, and the height difference correspond to voltage. John and his peer William elaborate on this when asked what happens to the energy, and William relates friction in the ski track to the light bulb:

I: But what happens to the energy?

John: They use it when they run downhill, and... you could say it is friction when they run downhill. And that is the way the energy is used. Not sure if this is right... they could just as well fall... William: yes, and then it is the light bulb in our case.

John: Yes, I don't know. They could run into a snowdrift also. And that is in a way the resistance in the circuit.

The students' responses illustrate how an analogy can be interpreted in different ways based on the same textbook. Even if John and William relate resistance to friction and physical obstacles rather than difference in height in the slope, they show a promising grasp of ideas involving potential and potential differences and the meaning of those concepts for energy transfer in a circuit.

\section{Analogy 2: Pipe system}

This analogy caused some initial confusion in all the student groups, due to the lack of clarity in the textbook drawing of the pump. Students refer to it as a fan, mill, resistor and generator. This means that the drawing, and the text as a whole, do not fill the purpose of analogies at the outset, that is, to compare a target domain to a familiar source domain. The problem may be a combination of the flaw of the drawing and the fact that a pump is not a familiar object in everyday life of today's teenagers. Still, students are able to relate current and the battery (source of voltage) to objects in the source domain, and to see relations between the source domain and the target domain in terms of energy transfer. What this means in concrete terms is, however a challenge for students. This is exemplified by how Jennifer and Susan reflect on what happens to the electrons when there is a light bulb (resistance) in the circuit:

Jennifer: Eh... it stops up in a way. It takes energy.

Susan: Or it transforms energy, doesn't it? In the light bulb, there the energy in the electrons will be transformed to light.

Jennifer: It will be transformed to kinetic energy... or it is already kinetic energy, but in a different 
form. And it can be transformed to electric energy later, since energy never disappears, sort of. I: Yes. But you said "stopped up". What did you mean with that?

Jennifer: Yes, well... because when the energy of the water arrives at the mill, the speed of the water, that is the kinetic energy of the water decrease...

The students themselves bring in the concept of energy, and they manage to express a shared relation with regards to the ability of water molecules and electrical charges to transfer energy in the system. They also seem to have a constructive understanding of similarities between energy transfer in the water pipe and in the electric circuit on a macroscopic level, that is, that the resistance in the bulb/ mill decreases the current. However, problems arise when the interviewer asks whether there is a difference in speed of the electrons before and after the bulb in the circuit:

I: Does the same happen in the circuit?

Jennifer: Eh, yes, I believe so. At least the battery will run out. So we use up the energy in the batteries because it is transformed to other kinds of energy.

I: Yes. But will the electrons move slower before or after the light bulb?

Jennifer: Eh... I don't know, from the example with water in a pipe system I feel it should, but I don't really believe so.

The sequence indicates that Jennifer actually has a better grasp of the target domain than the source domain. She has a conception of electric current as continuous, it is the same at all points of the circuit and increased resistance will cause lower current in the entire circuit. For the water pipe system, however, she indicates that she "feels" the water speed should be lower after the water has passed through the mill, and she is hence not sure about the shared relation between objects in the source domain and the target domain.

Another issue that is somewhat problematic in how the analogy is presented in the textbook is whether the pipe system involves a difference in height. In the following sequence, Robert and David takes as a starting point that the pump is pumping the water upwards, and it will then fall down on the turbine and make it run (Robert and David have had this analogy in their school textbook):

Robert: I imagine the pump pumping up like this.

I: You envision that the water goes upwards, so the pipe system has elevation?

Robert: Mm

David: Yes

Robert: The pump pushes the water up, and it sort of falls down on the turbine, but...

I: So it is important that the pipe system has a height?

Robert: Not really. Since you have a pump. It could lay flat, and pump around and around.

When challenged, Robert comes to the conclusion that the height as an attribute of the source domain is not relevant, since the pump will make the water flow anyway.

The concept of voltage is challenging to map in the analogy for all the students. This sequence shows that the issue is not trivial, even for John as a high-performing student (John and William have had this analogy in their school textbook):

I: Do you see any clear relations between the pump and the battery in the pipe system?

John: How hard the pump manages to pump the water, or how fast. No...not how fast perhaps. William: No.

John: But yes. The Ampere [current] will be how much water there is in the wire, or in the pipe system. I: But the voltage?

William: Well, that's the difficult part.

John: I think it is difficult also. If the pump pumps harder the water will get higher speed, but that is not the voltage...? So how can the pump be the source of voltage? 
John has problems seeing how the water pump can correspond to a source of voltage (battery), since increasing the power of the pump increases the speed of the water, not the amount. The corresponding relation in the electric circuit is that a higher number of electrons are "pumped" from the battery and thus increasing the current. Here, John's knowledge of the source domain as well as the target domain distracts his understanding of the analogy since he tries to map relations between potential energy from height difference to the battery's voltage. However, he does not attempt a mapping between pressure and voltage, and the presentation in the textbook does not directly invite him to do so..

The description of the pipe system as analogy is actually ambiguous in the textbook, where it is not clear whether the water is supposed to fall or if it is pumped around a circuit (which is laying horizontally). John sees a problem with the mechanics suggested in the drawing:

John: The point is that there is no fall energy since... because the whole thing is filled with water. So the water will never fall anywhere. It will only be pulled around and around forever.

As with the ski lift analogy, John here uses his knowledge of the source domain to question features of the analogy as presented in the textbook.

In sum, the way the textbook presents the water pipe system as an analogy for electric circuits seems to be problematic for students, since details in how the target domain maps the source domain are not made explicit for students. Further, the analogy may not function well as source domain because it does not represent experiences that students may draw on in attempting to understand electric circuits by means of the analogy.

\section{Analogy 3: Waterfall}

This analogy turned out to be better suited for discussions about the concept of voltage than the analogies 1 and 2. The concept is still challenging for the students, as shown in the following excerpt about relations between objects in the source domain and the target domain. The students are asked to identify relations between objects in the waterfall model and the electric circuit:

George: Resistance can be the path from the pump and up to the mountain top.

Mark: And the water is electrons.

George: Yes... and the battery could be this pump here... or that pond.

I: "The pond is the battery". Why is that?

Mark: It is the source of electrons in a way

I: What about the pump, then?

George: It is maybe... difficult. I would say that the battery is both the pump and the pond. Because then there are electrons there, and it is where electrons get energy because they are pushed upwards. Through that tap there, and there it let go. Then they travel down again to the storage, or the battery.

George identifies first the pond as corresponding to the battery. Prompted about the pump, he modifies his explanation to a combination of the pond and the pump, since the pump is needed to move the water (or: electrons) uphill in order to give them energy. It seems that Mark thinks of the battery as a 'storage' of electrons, resembling the pond's storage of water. This interpretation of the analogy makes sense of "storage" in the sense that it is the water or electrons loaded with potential energy that are stored in the pond or in the battery. This line of thinking is also evident in a student group that brings in gravity in their interpretation of the analogy. When asked about what relates to the battery in the waterfall analogy, Robert points to both the pump and the gravitational force:

Robert: I would almost say both the pump and the gravitational force, really.

David: Yes

I: The pump and the gravitational force?

Both students: Yes 
Robert: Because... or...in the setting with current and so the gravitational force does not mean anything, in a way. So if it is to make sense that it is there, it must be some voltage force that makes the water run.

Robert's argument is valid in that the pump alone would not make a current run in the circuit; it would just pump the water up the mountain. What makes the current run is the height combined with the gravitational force, leading Robert to see the battery as corresponding to both the pump and the gravitational force in the analogy. This makes sense since the essential shared relations with the electric circuit is that the mountain creates a difference in height that allows the gravitational force to make things fall.

\section{Analogy 4: Bowling balls}

The analogy involving a row of bowling balls makes more explicitly use of a shared relation involving a gravity field in the source domain and an electric field in the target domain. Since the concept of field is not included in the curriculum for lower secondary school (see NDET, 2013), the interviews focused on how the source domain relates to electric current and voltage, rather than the concept of field. None of the students came up with completely mapping of the domains, but still they managed to give some good reflections. In this sequence, Sara and Anna identify bowling balls as relating to electrons:

I: Do you see any relationship between the bowling balls and electric current?

Sara: Perhaps... the bowling balls are supposed to be electrons.

I: Electrons?

Anna: Yes, both the bowling balls and the electrons will move in a direction and...yes.

I: Yes?

Anna: They will move similarly... sort of.

I: What do you mean... move similarly?

Anna: Well... when that boy adds a new bowling ball, then all the balls will move the similar distance and... one will fall down and... I guess the same happens with electrons then...right?

Anna sees a shared relation between objects in the row of bowling balls and an electric circuit, in pointing to how the balls/electrons move "similarly". This means that their movement is continuous throughout the circuit. Like in a wave, it is the movement, not individual balls/electrons, that propagates through the entire circuit. From here, it is probably easy for students to accept that the current is the same at all places in the circuit, that is, Kirchhoff's first law.

The "heaviness" of the bowling balls is an attribute that makes it relatively easy to identify where the energy comes from, as students can easily imagine how the boy must use his muscles in lifting the balls. In the following sequence, John and George reflect on the bowling ball analogy with energy as a starting point. They soon arrive at a concept corresponding to electric potential, without having this concept as their vocabulary:

John: Well, those bowling balls are lifted up... and then they get more potential energy.

I: Yes. Can you see that in relation to the electric current?

John: Yes, I think... well, the electrons gain electric energy in the battery, sort of, so then the battery becomes the boy, and opposite.

I: What about electric voltage? What do you think about that concept in this model?

George: Perhaps... no... well, it is the boy that lifts the bowling balls, and the battery that lifts... no, it is perhaps not right to say.

I: Let's say "lifts". Go on, this is good.

George: Yes, well... it is the gravity that makes the balls roll. So then it must be energy that makes the electrons move... difference in energy perhaps, I don't know.

I: Difference in energy, what do you mean?

George: No, I don't know really. It is difficult, but I think it must have to do with difference in energy. 
George appears to have a clear conception of that the balls movement is caused by difference in energy, but he struggles to formulate what this means. He lacks the conceptual tools to map shared relations between the domains. It seems clear that this student would be able to do so if he had been acquainted with the concept of electric potential, corresponding to height in the analogy, and with electric voltage as the difference between levels of potential (/height). A more complete understanding of the circuit with energy, field and potential as starting points would probably be within reach for this student by means of the analogy with bowling balls.

\section{DISCUSSION}

All the students in our study seem to understand the general purpose of using an analogy. None of them seems to take them too literally as has been reported as a challenge in previous research (e.g. Treagust et al., 2002). It also appears that the students are able to map the concepts of continuity and driving force in the analogies. The results do, however, reveal severe problems for students in mapping the source domain to the target domain in complete ways. In some cases, these problems are caused by the source domain being unfamiliar to students when it comes to details, and to weaknesses in the textual and pictorial presentation of analogies in the textbooks. This mirrors how textbook analogies are often vague and potentially confusing.

Challenges occurred in particular when students discussed the pipe system (Analogy 2), where some students were unsure about what the effect of higher power in the pump is: Will the water go faster or will there be more water flowing? Combined with that this analogy was presented in unclear and ambiguous ways in the textbook, the analogy seems of little help to students who do not already know the subject content of the target domain (electric circuits). Similar problems with water reservoirs used in analogies for electric circuits were found by Gentner and Gentner (1983), and many have pointed to the importance of students being familiar with the source domain in order for analogies to be useful (see e.g. Dupin \& Johsua, 1989; Gilbert \& Justi, 2016). However, in our interview data, we found incidences of students actually being more familiar with the target domain (electricity) than the source domain (water systems).

For the pipe system, familiarity with the source domain can be ensured for example by letting students work practically with a physical model as reported by Paatz et al. (2004). However, it is just as important to make sure that the source domain, in this case the pipe system, is correctly represented in textbooks and other teaching material, not only with regards to the shared relations that is the core of the analogy. Other studies have shown that when analogies are used as teaching models, authors only emphasise the similarity perspective (see Gilbert \& Justi, 2016). Students in our study were able to detect flaws in how the pipe system is represented (for example that water will not fall in a vertical pipeline when the entire pipe system is filled with water). Clever students may be able to ignore flaws and irrelevant attributes in an analogy, but for weaker students they may cause confusion or misunderstanding, and the analogy may thus hinder rather than support learning. This is a challenge in the use of analogies more generally pointed to by Coll et al. (2005). In case of the ski lift analogy (Analogy 1), the fact that the lift runs on electricity, creating a surface similarity as described by Gentner and Toupin (1986), caused confusion for some students as the electricity is an attribute that seems to be shared but is not. In the source domain electricity is part of a relational structure playing the role of powering the ski lift, i.e. electricity is the source powering the ski lifts motion. However, in the target domain electricity is the overall phenomenon and therefore not a shared relation. Representations of the ski lift analogy should therefore avoid electricity as an energy source for the lift and rather present a motor using some sort of energy.

The concept of voltage caused problems for students in the present study, in compliance with other research results (see e.g. Cohen et al., 1983; Kokkonen \& Mäntylä, 2017). Students were able to identify the source of energy in most of the analogies and hence the object corresponding to the source of voltage (battery). It is, however, striking that several of the analogies are not clear on what it is in the 
source domain that corresponds to voltage, given that this is a very challenging concept for students. The analogy that seems to best provide for a constructive conceptualization of voltage was the bowling balls (Analogy 4) and the interpretation that the students John and William introduced with regards to the ski lift analogy (Analogy 1). Common to these two analogies is that they have height as a key object, and a shared relation with the target domain is that larger difference in height, corresponding to voltage, evokes more energy transfer. The corresponding object to height is electric potential, denoting a level where difference in level represents voltage. Even if the bowling ball analogy may support a mistaken idea about electrons moving in a linear and uniform way, it may be constructive in getting a grasp of the concept of voltage in terms of a difference in potential.

The reasoning about voltage as difference in potential compared to height difference would be more clear for the students if the concept of 'field' was included. A generalised concept of field is usually not taught in depth in lower secondary school science, but would make students able to map the gravitational field in a source domain to the corresponding electric field in the target domain and this way get a grasp of the concept of potential. It appears from our results that potential is a conceptual gap as described by Sangam and Jesiek (2015), and that some students would probably be able to map the analogies involving height and height difference if they had this concept as a tool. In line with Stocklmayer (2010), we suggest that further research should be undertaken in order to elicit whether and in what ways the concepts of field and potential should be introduced for supporting young students understanding of electric circuits and improving their understanding of electric voltage as a key concept. This may prevent the unconstructive conceptions and explanation models that research has shown that more advanced students may hold about relatively simple electric circuits (Kokkonen \& Mäntylä, 2017; Periago \& Bohigas, 2005). Since field and potential are very abstract concepts, it should be noted that the sample of students in the present study do not include the weaker students. When our results indicate that lower secondary students may be able to grasp these abstract concepts, it may not apply to all students in a class. This is a limitation of our study.

\section{CONCLUSION AND IMPLICATIONS}

Through many years, science education research has investigated the use of analogies in teaching and learning science, including analogies for electric circuits. However, textbook analogies in this topic remain challenging for students, and our results show that this is in particular the case for the concept of voltage and how this concept is represented in the source domain. It is a cause for concern that analogies commonly presented in school science fail to build a fruitful understanding of the concept that research has shown is most challenging for students.

Results indicate that analogies involving height differences in the source domain can help students to build a constructive conception of voltage. This requires, however, that students are provided with a concept of potential and a generalised concept of field. Since this involves quite some abstraction, it is an important issue for further research to investigate whether this also will work for students of lower ability than those interviewed in the present study.

As underlined by Gilbert and Justi (2016) and others, students need to be confident about the content in the source domain in order to benefit from the use of analogies. It seems from our results that this is not always the case for textbook analogies. For the analogy with a water pipe system in particular, students have problems in comprehending the overall system as well as what it means that the water current changes. The problem may partly be that today's young people lack direct experience with water pipes, but also that the textbook presentation lacks clarity and sufficient precision. On a whole, our empirical results show that textbook presentations of analogies have serious weaknesses that confuse students. This should be a major concern for authors of textbooks and other teaching material. 


\section{REFERENCES}

Braun, V., \& Clarke, V. (2006). Using thematic analysis in psychology. Qualitative Research in Psychology, 3(2), 77-101.

Brown, D. E., \& Clement, J. (1989). Overcoming misconceptions via analogical reasoning: abstract transfer versus explanatory model construction. Instructional Science, 18(4), 237-261. doi:10.1007/BFo0118013.

Brown, S., \& Salter, S. (2010). Analogies in science and science teaching. Advances in Physiology Education, 34(4), 167-169. doi:10.1152/advan.00022.2010

Bungum, B. (2008). Images of physics: an explorative study of the changing character of visual images in Norwegian physics textbooks. NorDiNa, 4(2), 132-141.

Chiu, M.-H., \& Lin, J. (2005). Promoting fourth graders' conceptual change of their understanding of electric current via multiple analogies. Journal of Research in Science Teaching, 42(4), 429464. doi:10.1002/tea.20062

Cohen, L., Manion, L., \& Morrison, K. (2011). Research methods in education. London and New York: Routledge.

Cohen, R., Eylon, B., \& Ganiel, U. (1983). Potential difference and current in simple electric circuits: A study of students' concepts. American Journal of Physics, 51(5), 407-412. doi:10.1119/1.13226

Coll, R. K., France, B., \& Taylor, I. (2005). The role of models/and analogies in science education: implications from research. International Journal of Science Education, 27(2), 183-198. doi:10.1080/0950069042000276712

Duit, R. (1991). On the role of analogies and metaphors in learning science. Science Education, 75(6), 649-672. doi:10.1002/sce.3730750606

Dupin, J. J., \& Johsua, S. (1989). Analogies and "Modelling Analogies" in Teaching: Some examples in Basic Electricity. Science Education, 73(2), 2017-2224.

Ekeland, P. R., Johansen, O.-I., Strand, S. B., Rygh, O., \& Jenssen, A.-B. (2008). Tellus 9 (2 ed.). Oslo: Aschehoug.

Gentner, D. (1983). Structure-Mapping: A Theoretical Framework for Analogy. Cognitive Science, 7(2), 155-170. doi:10.1207/s15516709cog0702_3

Gentner, D., \& Gentner, D. (1983). Flowing waters or vTeeming Crowds: mental Models of Electricity. In D. Gentner \& A. L. Stevens (Eds.), Mental Models (pp. 99-129). Hillsdale, London: Lawrence Erlbaum Associates.

Gentner, D., \& Toupin, C. (1986). Systematicity and surface similarity in the development of analogy. Cognitive Science, 10(3), 277-300. doi:https://doi.org/10.1016/So364-0213(86)80019-2

Gilbert, J. K., \& Justi, R. (2016). Modelling-based Teaching in Science Education: Springer.

Glynn, S. M. (1989). The teaching with analogies (T.W.A.) model: Explaining concepts in expository text. . In K. D. Muth (Ed.), Children's comprehension of narrative and expository text: Research into practice (pp. 99-129). Newark, Delware: International Reading Association.

Glynn, S. M., \& Takahashi, T. (1998). Learning from analogy-enhanced science text. Journal of Research in Science Teaching, 35(10), 1129-1149. doi:10.1002/(sici)10982736(199812)35:10<1129::Aid-tea5>3.0.Co;2-2

Hannisdal, M., Haugan, J., \& Munkvik, M. (2007). Eureka 9 (1 ed.). Oslo: Gyldendal Norsk Forlag.

Harrison, A. G., \& Treagust, D. F. (1993). Teaching with analogies: A case study in grade-10 optics. Journal of Research in Science Teaching, 30(10), 1291-1307. doi:10.1002/tea.3660301010

Hedberg, D., Haglund, J., \& Jeppsson, F. (2015). Metaforer och analogier inom termodynamik i kemiläroböcker för gymnasiet. 102-117. NorDiNa, 11(1), 102-117.

Jerstad, P., Sletbak, B., Grimenes, A. A., \& Renstrøm, R. (2007). Rom, Stoff, Tid. Fysikk 1. Oslo: Cappelen.

Kokkonen, T., \& Mäntylä, T. (2017). Changes in University Students' Explanation Models of DC Circuits. Research in Science Education, 1-23.

Koponen, I. T., \& Huttunen, L. (2013). Concept Development in Learning Physics: The Case of Electric Current and Voltage Revisited. Science \& Education, 22(9), 2227-2254. doi:10.1007/ s11191-012-9508-y 
Kärrqvist, C. (1985). Kunskapsutveckling genom experimentcentrerade dialoger i ellära. Dr. thesis, Gothenburg University.

Leone, M. (2014). History of Physics as a Tool to Detect the Conceptual Difficulties Experienced by Students: The Case of Simple Electric Circuits in Primary Education. Science \& Education, 23(4), 923-953. doi:10.1007/s11191-014-9676-z

Liégeois, L., \& Mullet, E. (2002). High school students' understanding of resistance in simple series electric circuits. International Journal of Science Education, 24(6), 551-564. doi:10.1080/09500690110066520

Mogstad, E. (2016). “Elektriske analogier”: En kvalitativ studie av analogier i læremidler for undervisning om elektrisitet. (Master thesis), NTNU, Trondheim.

NDET. (2013). Natural Science subject curriculum. Retrieved February 2018 from https://www. udir.no/klo6/NAT1-o3?lplang=http://data.udir.no/klo6/eng. Oslo: Norwegian Directorate for Education and Training.

Paatz, R., Ryder, J., Schwedes, H., \& Scott, P. (2004). A case study analysing the process of analogybased learning in a teaching unit about simple electric circuits. International Journal of Science Education, 26(9), 1065-1081.

Periago, M. C., \& Bohigas, X. (2005). A study of second-year engineering students' alternative conceptions about electric potential, current intensity and Ohm's law. European Journal of Engineering Education, 3o(1), 71-80. doi:10.1080/03043790410001711225

Rengman, H., Johansson, H., \& Jeppsson, F. (2010). Den elektriska kretsen - En explorativ studie av svenska elevers uppfattningar angående den elektriska kretsen. NorDiNa 6(2), 173-191.

Rossing, N. K. (2005). Fra elektrisk krets til intelligent hus. Kurshefte. Trondheim: Skolelaboratoriet for matematikk, naturfag og teknologi, NTNU.

Sanders, W. L., Wright, S. P., \& Horn, S. P. (1997). Teacher and Classroom Context Effects on Student Achievement: Implications for Teacher Evaluation. Journal of Personnel Evaluation in Education, 11(1), 57-67. doi:10.1023/a:1007999204543

Sangam, D., \& Jesiek, B. K. (2015). Conceptual gaps in circuits textbooks: A comparative study. IEEE Transactions on Education, 58(3), 194-202.

Shipstone, D. M., Rhöneck, C. v., Jung, W., Kärrqvist, C., Dupin, J. J., Johsua, S., \& Licht, P. (1988). A study of students' understanding of electricity in five European countries. International Journal of Science Education, 10(3), 303-316. doi:10.1080/0950069880100306

Stocklmayer, S. (2010). Teaching direct current theory using a field model. International Journal of Science Education, 32(13), 1801-1828.

Tarciso Borges, A., \& Gilbert, J. K. (1999). Mental models of electricity. International Journal of Science Education, 21(1), 95-117. doi:10.1080/095006999290859

Thiele, R. B., \& Treagust, D. F. (1994). The nature and extent of analogies in secondary chemistry textbooks. Instructional Science, 22(1), 61-74. doi:10.1007/bfoo889523

Treagust, D. F., Chittleborough, G., \& Mamiala, T. L. (2002). Students' understanding of the role of scientific models in learning science. International Journal of Science Education, 24(4), 357368. doi:10.1080/09500690110066485 